\title{
WE'LL BUILD IN SONNETS PRETTY ROOMS: UNA NUEVA MIRADA A LA POESÍA INGLESA DEL SIGLO XVII
}

\author{
Juan de Dios Torralbo Caballero \\ University of Cordoba \\ torralbocaballero@uco.es
}

doi:10.13165/SMS-13-5-4-06

Resumen. La imbricación de sociedad y literatura es un fenómeno tangible en la poesía inglesa del siglo XVII. Este artículo pone de manifiesto las relaciones entre la creación artística y el factor político, comenzando por la poesía petrarquista que recala en los sonetos de la era isabelina para pasar después a las escuelas metafísica (Donne) y "cavalier" (Jonson). El estudio prosigue con la poesía religiosa (Herbert), puritana (Milton) o libertina (Rochester) deteniéndose también en la literatura escrita por mujeres (Behn) $o$ en los poetas que funden el paisaje con la alabanza a poderosos y protectores (countryhouse poems). Partiendo del verso "We'll build in sonnets pretty rooms", de John Donne, este trabajo trata de presentar un recorrido exhaustivo por la poesía del siglo XVII indagando de esta forma en los diferentes estilos que son cultivados por cada uno de los grupos de poetas. Se aborda el soneto en la obra de Wyatt, Howard, Sidney, Spenser, Shakespeare, Donne, Herbert y Milton. Seguidamente, se estudia el nuevo universo que puebla el verso de los poetas metafísicos para destacar algunas de sus características retóricas como es el caso del "conceit", la mezcolanza entre la nueva "ciencia" y la filosofía así como el estilo complejo que aplican en los poemas. El siguiente grupo que se analiza es el de los poetas "Cavalier" que aplican brevedad y elegancia en unas piezas poéticas breves y pulcras desde el punto de vista estilístico y muy comprensibles desde el punto de vista semántico. La poesía religiosa también es tratada de forma pormenorizada porque hay un número de escritores

Socialiniu mokslų studijos / Societal Studies

(c) Mykolo Romerio universitetas, 2013

(C) Mykolas Romeris University, 2013
ISSN 2029-2236 (print), ISSN 2029-2244 (online) http://www.mruni.eu/lt/mokslo_darbai/SMS/ http://www.mruni.eu/en/mokslo_darbai/SMS/ 
significante que dedican su esfuerzo a la introspección devocional y a la postulación de la fe cristiana. Como contraste, se indaga en la poesía libertina que va más allá del carpe diem cultivado por los Cavaliers. Finalmente se presenta el logro y la conquista de la mujer como escritora en la Inglaterra del siglo XVII para terminar con otro tipo de poesía que fusiona el paisaje con la política y la sociedad ("country-house poems").

Palabras clave: Poesía metafísica, poetas cortesanos, poetas devocionales, ingenios femeninos, poemas "country-house".

\section{Introducción}

Isabel Tudor comienza su reinado en 1558, al frente de una nación deprimida, tal como refleja el documento "The Distresses of the Commonwealth" ${ }^{1}$. De este panorama, brotarán nuevos tiempos tanto sociales como creativos que alcanzan su apogeo en los poetas representativos del Renacimiento, como son Phillip Sidney o Edmund Spenser, quienes ven el final de sus días con el ocaso del siglo XVI, en 1586 y 1599 respectivamente.

En materia de poesía, se estrena el nuevo siglo con la pervivencia del predicamento de Sidney y Spenser junto al todavía vigente de Sir Walter Raleigh. La sinergia que hace florecer nuevos poetas en la nueva era parte, claramente, de los logros que se materializan durante el último decenio del siglo XVI. A la vez se publican versos de Campion, Drayton, Daniel y Shakespeare. 1609 queda como un año clave al ver el genio isabelino publicados sus Sonetos. Uno de los poetas estudiados en este artículo, John Donne, compone "The Cannonization" donde proclama que labrarán bellas moradas en los sonetos, concretamente en la cuarta estrofa de este emblemático poema: "We'll build in sonnets pretty rooms / As well a well-wrought urn becomes". Esta afirmación predice un cambio en la literatura inglesa que luego toma caminos diversos al compás de los acontecimientos socio-políticos y en consonancia con la singularidad de cada poeta.

Este artículo se centra en la poesía, dejando fuera al teatro. En 1570 Abraham Ortelius publica en Amberes su atlas Theatrum orbis teatrum, poblado de mapas y de referencias bibliográficas. En 1606 se traduce al inglés. La concepción del mundo como escenario también subyace en el mismo nombre de la compañía teatral de Shakespeare, "The Globe". El escenario permite un desarrollo notable de la literatura inglesa, tanto en las épocas isabelina y jacobina, como en los tiempos de Carlos I. En cada momento la obra de arte verbal refleja la idiosincrasia social y política. En la República los teatros son clausurados y con la Restauración (Carlos II) ven un claro renacer que se eclipsa, de nuevo, en los últimos años del siglo. Las representaciones teatrales, que comienzan ligadas a la liturgia religiosa (los milagros, las ceremonias, las representaciones) se convierten

1 Hermann, P. C., A Short History of Early Modern England. British Literature in Context. Oxford, Willey-Blackwell, 2011, p.115.

2

Sell, J. P. A., Conocer a William Shakespeare, Madrid, Laberinto, 2012, p.49. 
en una fuente de placer para nobles y las clases más pudientes llegando también a ser accesibles a la plebe.

\section{El contexto social y político}

El año 1603 ve morir a Isabel I y llegar al trono a Jacobo I quien apoya a la compañía de actores de Shakespeare (Lord Chamberlain's Men) que pasan a llamarse The King's Men. Ahora es cuando Samuel Daniel publica A Defence of Rhyme. Pero no todo son efemérides porque una peste asola Londres durante el verano, diezmando a la población; muere uno de cada cuatro habitantes.

Desde 1625 hasta 1630 hay una sequía productiva. En 1625 asciende Carlos I al trono. Hay una peste. En 1626 se produce la guerra con Francia. Entretanto, el Parlamento se congrega y se disuelve. En 1630 muchos ingleses emigran para Nueva Inglaterra, siguiendo la estela que diez años atrás inaugura el centenar de peregrinos que se establece en Massachusetts.

En 1640 destaca la convocatoria del Parlamento, tras once años sin reunirse, que al poco se disuelve. Por eso se conoce como el Parlamento Corto (Short Parliament). Carlos I deseaba obtener dinero para de esta forma luchar contra los escoceses que se han levantado en rebeldía. Meses después, el Parlamento es convocado de nuevo, en este caso se conoce como el Parlamento Largo (Long Parliament). Las decisiones tomadas en el Parlamento van consolidándose hasta tal punto de reprobar la política del rey. Cuando proponen a Carlos I que sea el Parlamento quien tome las riendas de los ejércitos están detonando la guerra entre los realistas y los parlamentaristas que se encarniza en 1642 y se propaga hasta 1648 .

El 6 de septiembre de 1642, los puritanos prohíben los teatros. Los defensores del rey Carlos I se enfrentan a las tropas del bando parlamentario capitaneadas por Oliver Cromwell. Surge entonces una escritura a favor de uno u otro bando. Además, también emana un tipo de verso fervoroso y una prosa religiosa. Esta escritura parece la tabla de salvación de los graves problemas que azotan al país. En 1649 llevan a Carlos I a la horca, una vez que es condenado por alta traición. Es decapitado el 30 de enero de 1649 como si de un espectáculo público se tratara, en la zona exterior del palacio de Whitehall. Comienza la Commonwealth, la república de Oliver Cromwell, que ostentará el título de Lord Protector (1653).

Entonces se articula una copiosa prosa de carácter político y religioso capitaneada por Milton, a la que se suma Hobbes con dos publicaciones. Del puritano sobresalen sus defensas Eikonoklastes (1649) y luego Defensio pro Populo Anglicano (1651). Del filósofo nombramos Leviathan, or the Matter, Forme, and Power of a Common Wealth Ecclesiasticall and Civil (1651), así como De Corpore Politico (1655). En 1658, Richard Cromwell toma el timón del Estado hasta que, sin apoyos, presenta su renuncia en 1659. En 1660 algunos generales invitan a Carlos II para que retorne de su exilio y, de esta forma, instaurar la vieja forma de gobierno, la dinastía Estuardo.

Cambia el panorama en Londres y el futuro rey suaviza sus posturas. En abril de 1660 firma la Declaración de Breda (Declaration of Breda) que nombra el derecho divino de sucesión al tiempo que predice una amnistía para los enemigos de su padre así como la 
tolerancia religiosa. En mayo de 1660 el monarca es recibido con júbilo y esperanza. El rey trae el nuevo horizonte estético que ha visto en Francia. Así se reflejará en el teatro y en la poesía.

Desde 1682 hasta 1694 merman las publicaciones literarias. Durante estos años proliferan, entre otros trabajos, una obra religiosa de Dryden, la prosa de Bunyan, los poemas de Edmund Waller (1685), de Thomas Killigrew (1686), el tratado de Newton (1687) y la filosofía de Locke $(1689,1690)$. Particularmente, en 1682 "Duke’s Company" incorpora a "King's Company" a su séquito, resultando la fusión en "United Company" cuyo interés se dirige a la tragedia en detrimento de la comedia. Hay una crisis en el teatro. La década de los 80 es pródiga, sin embargo, en poesía y narrativa como denota el esfuerzo de Aphra Behn.

En febrero de 1685 muere Carlos II y es coronado su hermano como Jacobo II. Cuatro meses después, el duque de Monmouth (hijo ilegítimo del fallecido monarca) se rebela enviando sendos buques al puerto de Dorset y difundiendo un comunicado en defensa propia y contra su tío el duque de York.

1688 es el año de la Revolución Gloriosa, llamada también la Revolución sin sangre (Bloodless Revolution) porque se va a producir un derrocamiento que en nada se parece a las contiendas civiles libradas unas décadas antes. Jacobo II aboga por suprimir las homilías que contengan ideas contra los católicos y, en este sentido, hace gala de su tolerancia religiosa. Este apoyo hacia el catolicismo arrecia las críticas de los protestantes que ven en el nacimiento del heredero (1688) una amenaza mayor. Se desencadena una crisis política. En noviembre de 1688 Guillermo de Orange invade Inglaterra (provocando la huída del rey a Francia) con una flota holandesa y un ejército proclamándose como Guillermo III de Inglaterra en febrero del año siguiente, junto a su esposa María II de Inglaterra que es hija del depuesto rey.

La última etapa del siglo ve publicadas obras filosóficas y políticas, como son Essay Concerning Human Understanding y Some Thoughts Concerning Education de John Locke; teatrales como The Double Dealer o Love for Love de William Congreve y líricas como Alexander's Feast de Dryden. Acaece también, en el plano económico, la fundación del Banco de Inglaterra y del Banco de Escocia. El fin de siglo está marcado por tres acontecimientos relacionados directamente con el mundo literario. En 1700 se publica The Way of the World de Congreve; el 1 de mayo de 1700 muere Dryden y este mismo año se difunde The Dumb Virgin de Aphra Behn.

\section{Petrarquismo y concentración retórica en el soneto}

La raíz se sitúa en Petrarca que canta a Beatriz. Dante, por su parte, canta a Laura. La temática omnipresente en los sonetos es el amor. Este género literario aprieta en sus catorce versos varias estrofas que a su vez configuran un puñado de figuras retóricas que se asocian con una magistral concentración, como si se tratara de un diminuto campo de energía cargado de emociones y artificios ${ }^{3}$. El marco formal es conciso y concentrado 
permitiendo, mediante la intensidad emocional, el desarrollo de un argumento lógico que en ocasiones da respuesta a un problema en el apartado final que actúa a modo de conclusiones, vistas las premisas del silogismo.

Los inauguradores del género en el archipiélago inglés son Sir Thomas Wyatt y Henry Howard (Surrey). Los ingleses emulan la elocuencia latina e italiana. Wyatt escribe 76 sonetos de amor y 20 de otros temas; Howard compone unos 26 amorosos y 14 sobre otros asuntos. A ellos les corresponde la primacía de haberlo importado. Este modo compositivo denota el carácter cortesano de la poesía, retomando la tradición de Horacio, Virgilio y Ovidio y, de modo más inmediato, las secuencias de pasión y amor de Vita Nuova y Canzionere. El mismo George Puttenham en su The Art of English Poesie reconoce la labor de Wyatt y Howard y aplaude la entrada foránea desde los manantiales latinos e italianos.

El soneto está en boga durante la época isabelina. Varios son los sonetistas que han quedado inmortalizados en la historia literaria por haber compuesto una brillante serie de poemas, como es el caso de Sir Philip Sidney, con los 108 sonetos de Astrophil and Stella y Edmund Spenser con Amoretti. El último verso del primer soneto de Sidney deja claro el carácter introspectivo que la estrofa pone de manifiesto, escudriñando en los estados anímicos de los autores que, en muchas ocasiones, están proyectados en los personajes. La intimidad está relacionada con la brevedad ${ }^{4}$. Reluce la individualidad del escritor, tal como enclaustra Sidney en el último verso de su primer soneto: "Foole', said my Muse to me, 'look in thy heart and write"'. También se entrevé la dedicación que el hacedor ha de aplicar para lograr estas bellas piezas.

El escritor está meditando públicamente sobre los entresijos del amor. El poeta lo hace circular en manuscrito y es de forma póstuma cuando Thomas Newman lo publica. El manuscrito encarna los valores aristocráticos, de un cortesano que ilustra los valores dichos por Castiglione en Il Cortesano; sin embargo, no queremos soslayar la ordenación de los poemas, similar en todas las ediciones, que denota la consideración del lector por parte de su autor. Sidney, como mecenas de poetas, ejemplifica unos rasgos caracterológicos aristocráticos.

Edmund Spenser, por su parte, prepara su serie un año después de contraer matrimonio con Elizabeth Boyle y muestra el cortejo a la dama. En este sentido, la temática de Spenser es inédita porque celebra el amor correspondido y traza la evolución desde el cortejo al matrimonio, sin desdeñar las profundidades espirituales. Los temas recurrentes en el soneto versan sobre el amor atormentado que padece el poeta-amante o el rechazo de la amada, no estando el lector acostumbrado al tono de Spenser.

Shakespeare plantea asuntos diversos como la fugacidad de la vida y el paso del tiempo a través de los conocidos como "when-when-then sonnets", sin dejar de lado los poemas de indagación sentimental en otros conocidos como "catalogue-sonnets". Esta serie denota privacidad ${ }^{6}$ ya que son escritos para que circulen entre una audiencia. Los

4 Spiller, M. R. G., "The Sonnet and its Space” in The Development of the Sonnet. An Introduction, London \& New York, Routledge, 1992, p.8.

5 Roche, T. P., "Shakespeare and the Sonnet Sequence" in C. Ricks (ed). English Poetry and Prose, 1540-1674. The Penguin History of English Literature. Vol 2, Harmondsworth, Penguin, 1970, p. 73-89. 
126 primeros hablan del amor con el joven bello de clase alta, en tanto que el siguiente bloque $^{7}$ alude a una dama oscura que comienza exhortando al protagonista a lograr la inmortalidad a través del matrimonio, su descendencia y la poesía. Al integrar en los sonetos a un posible amor homo-erótico, Shakespeare está agrandando los cauces del género si nos ceñimos a la relación hetero-erótica que se vierte en Petrarca, Dante, Sidney o Spenser.

Durante el siglo XVII pervive la tradición del soneto pero hay que mencionar que va sufriendo un declive para ir desapareciendo del mapa literario en las últimas décadas y permanecer así en penumbra hasta que el género reviva a manos de poetas como Charlotte Smith que van conduciendo la estrofa hacia la eclosión del Romanticismo. Los asuntos abordados en el soneto también abarcan una temática religiosa la cual hace gala, igualmente, de la retórica del amor como se observa en los sonetos del que fuera deán de la Catedral de San Pablo.

Holy Sonnets de John Donne son 19 poemas de temática divina que ven la luz en 1633, dos años después de la muerte del poeta, en la serie Songs and Sonnets, habiéndose leído previamente en formato de manuscrito. Compuestos por dos cuartetos y un sexteto, de estilo petrarquista, incorporan en ocasiones un pareado final, lo cual revela cierto influjo shakespereano. La obra pone de manifiesto rasgos religiosos de carácter general junto a otros indiciarios semánticos de índole más personal como la conversión, el amor de Dios y la vocación del sacerdote. El soneto XIV clama la presencia de Dios en una métrica novedosa que cambia la alternancia de los yámbicos por acentos seguidos más contundentes para conceptualizar al sujeto lírico bajo la imagen de una ciudad que quiere sea habitada y defendida por Dios frente a las fuerzas del mal de los enemigos: "Batter my heart, three-person'd God; for you / As yet but knock; breathe, shine, and seek to mend".

Donne dedica sus sonetos a Magdalen Herbert, benefactora del escritor y madre de George Herbert, que en 1610 le entrega unos sonetos siguiendo el modelo inglés de anatomía shakespereana del que varía el tercer cuarteto (effe). Herbert en las piezas que envía a su madre se dirige abiertamente a Dios para defender que los sonetos son dignos de albergar el amor divino, abogando pues por poemas desprovistos del ornato superfluo y buscadores del amor sobrehumano. Así lo aclama en el primer cuarteto de este soneto que comienza con un vocativo al receptor:

My God, where is that ancient heat towards thee,

Wherewith whole showls of Martyrs once did burn,

Besides their other flames? Doth Poetry

Wear Venus livery? only serve her turn?

Herbert, que aplica el alegato del estilo llano que explaya en "Jordan" lleva la deseada transparencia al título y de esta forma encontramos "Holy Baptisme I", "Love I", "Love II", "Prayer I", "Redemption", "Sinne I" o "The Holy Scriptures”. Esta temática centrada en el amor divino y en torno al rito eclesiástico es similar a la que hallamos en algunos sonetos

in Cousins, A. D. \& Howarth, P. The Cambridge Companion to The Sonnet, Cambridge, Cambridge University Press, 2011, p.68. 
de John Milton, quien también desgrana el tema religioso en alguno de sus sonetos. Pero en este caso llama más la atención los asuntos de trasfondo político y social.

John Milton cultiva el soneto italiano que introduce Wyatt. Una primera tirada de sonetos se lee en 1645, en Poems of Mr. John Milton, both English and Latin, Composed at several Times a los que le añade otros en la nueva edición de 1673. El poeta puritano tiene en su biblioteca el libro de Giovani della Casa titulado Rime e Prose (1629). De aquí toma la sintaxis y la métrica; della Casa rompe la regularidad petrarquista. En cuanto a los temas, el soneto va a pasar de la privacidad hacia una dimensión más pública. El soneto estaba asociado a los temas de amor, pero ahora cambia la tendencia, pues Milton integra historia, política y religión. Porque se registran sonetos dirigidos a personas como Cromwell, Vane o Fairfax. Hay que decir que algunos están omitidos en la edición de 1645 por motivos políticos. En Tasso se lee un antecedente en lo que atañe a la tópica heterogénea, concretamente en sus decenas de sonetos sobre asuntos morales.

En general, destacan tres piezas de carácter personal, el XXII que comienza "Methought I saw [...]" que se refiere a su difunta esposa, otro de claros ecos shakespereanos es el soneto XII cuyo inicio es "How soon hath time [...]" y el conocido XIX sobre "When I consider how my light is spent" que tanto alude a su ceguera como a su esterilidad creativa buscando consuelo en su tesón y constancia. Aquí está grabada la ceguera del poeta, retomando el comienzo del soneto XV de Shakespeare ("When I consider everything that grows"). Contrasta la oscuridad con la luz. Esta composición, que data de 1652, aparece publicada en la reedición de sus poemas, en 1673. La octava del soneto, de estructura italiana, alivia su pesar, mediante la Paciencia personificada y portadora de un claro mensaje evangélico que ejemplifica con quienes sirven a Dios y acatan el yugo llevadero.

Con todo, la secuencia de Milton se compone de 23 sonetos, de los que cinco están escritos en italiano y 18 en inglés. Además hay una canción y un soneto con estrambote. La lectura atenta de los mismos sirve de fuente para ver la evolución del poeta, reflejando asuntos de diversas épocas entremezclados con respuestas teológicas y metafísicas. Además de los poemas dirigidos a personas contemporáneas (apostrophic sonnets), hay otros sobre la propia carrera del poeta siendo algunos proteicas afirmaciones de sus valores, bien de modo directo, bien por vía negativa. Los versos del escritor no se desprenden de su estilo latinizante y de su permanente uso del hipérbaton.

El poema a Sir Henry Vane es una muestra de la devoción del autor por el bando parlamentario, en este caso ilustrado en la persona de un diplomático que morirá defendiendo sus ideales. La composición dirigida a Sir Thomas Faixfax cuenta la historia de un general parlamentario realzando sus valores heroicos y sus atributos clásicos. Se inserta a continuación el soneto al general Cromwell que es un elogio a la fortaleza moral, a las cualidades del líder y al sentimiento religioso del caudillo republicano del que ensalza los triunfos militares y su restauración de la paz interna en el país. Comienza así: "Cromwell, our chief of men, who through the cloud / Not of war only, but detractions rude".

A partir de ahora, el soneto presenta un letargo en la literatura inglesa que abarca los últimos decenios del siglo XVII y el XVIII, volviendo a emerger en el siglo XIX, donde servirá, igualmente, de marco genérico tanto para el soneto ocasional como para la escritura de calado político. 


\section{El nuevo universo: la poesía metafísica}

La poesía metafísica rompe con la tradición. Plasma un nuevo universo y una ciencia que está en ciernes. Todo esto lo refleja el poeta mediante un lenguaje aparentemente árido y brusco. Así es el camino emprendido por John Donne con su poesía metafísica, cargada de resonancias inauditas hasta la fecha; poco familiares en la poesía.

No es normal recrear el símil de un compás en los versos. El lector no está acostumbrado a tener que escudriñar demasiado en la imaginería poemática para entresacar su significado. Tampoco es normal una escritura increpante contra el sol por el mero hecho de resplandecer y romper con su luz la intimidad de una pareja que, dentro de su dormitorio, se ven intimidados por la llegada del astro. La paradoja que expande "The Flea" tiene un tratamiento, por un lado, conyugal y por otro sagrado. Insólito resulta, asimismo, que el poema hable de explorar nuevos mundos y se empecine en indagar sobre asuntos tales como la ontología, la escatología o la cosmología. Estos poetas prodigan su agudeza en el verso.

Los inicios de la colonización que llevan a cabo los ingleses emigrados a América albergan un eco en algunos de los poemas que se están escribiendo mientras en las Islas. Además de la literatura de viajes, los nuevos territorios resuenan en piezas memorables como "Virginia" (Raleigh), "The Anatomy of the World" (Donne) o "Bermudas" (Marvell), o en otras donde los cuerpos toman las coordenadas de los mappae mundi. Así pues, la escena científica del momento se refleja en la poesía metafísica, aunque también llega a otros géneros y modalidades literarias tal como demuestra la pieza teatral representada en 1634, titulada Coelum Britannicum en la que Thomas Carew impregna su autoría con la cosmología y física de Giordano Bruno.

El poeta metafísico hace gala de su ingenio en tanto que interpreta la vida a través de su verso ${ }^{8}$. La rareza que ponen en el papel estos poemas es un uso impropio de las palabras, un empleo poco familiar abusando del estilo y llevando al lector a una especie de catacresis. A esto se suma la ironía que algunas líneas destilan y el uso del conceit.

Son muchos los recursos que despuntan en los poemas metafísicos que se llenan en ocasiones de filosofía, sapiencia y conocimiento. Además de los ya nombrados, incorporan el uso de figuras geométricas con un lenguaje proteico e hiperbólico que se concitan en la creación de la artificialidad de los versos. Watson ${ }^{9}$ alude a las metáforas omnipresentes en los versos metafísicos, al uso figurado del lenguaje, al etilo narrativo, al monólogo dramático, al comienzo abrupto de las composiciones in media res. Véanse si no los comienzos abruptos tomados de "The Flea" y "The Sun Rising", el primero comenzando por un imperativo ("Mark but this flea, and mark in this") para recalar en la tradición aristotélica de la mezcla de sangre que emplea Ofilius Sergianus ${ }^{10}$, el segundo

Williamson, G., "The Context of Metaphysical Wit", A Reader's Guide to the Metaphysical Poets, London, Thames \& Hudson, 1968, p.11.

9 Watson G., "The Language of the Metaphysicals" in G. Watson (ed.), Literary English since Shakespeare, Oxford, Oxford University Press, 1970, p.156-174. 
increpando contra el sol de modo rotundo ("Busy old fool, unruly Sun, / Why dost thou thus, / Through windows, and through curtains, call on us?")

La luz que penetra cortinas y ventanas llega al microcosmos del dormitorio que simboliza el centro del universo, dejando patente la revolución copernicana. El verso 30 lo objetiva todavía más: This bed thy centre is, these walls, thy sphere. Es decir, la cama es el centro del universo, que está delimitado por las paredes, allende las cuales está el sol. El poema presenta un espacio reducido a la pareja. La presencia de elementos redondeados es alta en "A Valediction: of Weeping" donde con el pretexto del llanto de una despedida nos encontramos con lágrimas, monedas, frutas, esferas, lunas, mares o mundos junto a una referencia al globo.

Es tangible la mezcolanza de temas cotidianos con asuntos complejos de más envergadura así como la distancia entre significante y significado que el lenguaje presenta. Es Eliot en 1921 quien rescata la poesía metafísica de las garras del olvido señalando el contenido intelectual que destila esa forma de "rapid association of thought" que demanda un esfuerzo interpretativo por parte del lector.

La constelación de poesía metafísica la componen, entre otros, John Fletcher, William Drummond, William Browne, George Herbert, Henry Vaughan, James Shirley, William Cartwright, Richard Crashaw y en cierto modo otros de retórica más heterogénea como son Andrew Marwell o Abraham Cowley. Este ingenio, wit, que podemos comparar con el de Baltasar Gracián, puede estudiarse a la luz del conceptismo de Quevedo o el culteranismo de Góngora. Wit es ingenio, sutileza y habilidad, es la agudeza similar al concetto italiano.

\section{Los poetas "Cavaliers": amor, brevedad y elegancia}

En el periodo isabelino surge un modo lírico que cristaliza en los poetas denominados caballeros. Se trata de piezas, por lo general breves, dirigidas a una mujer bella que, a diferencia de la dama que se sublima en la tradición petrarquista, está tratada de forma directa. Si en la tradición emanada del petrarquismo la señora es similar a una diosa, en esta tradición de poetas la protagonista es de carne y hueso, a la que el poeta habla con un tono más cercano. Muestran su ingenio y el carácter musical y cautivador de la poesía, abriendo un camino diferente al prendido por Donne.

La individualidad, el amor, lo casual y el ideal de caballero renacentista componen el corolario temático de estos poetas que esquivan los asuntos caballerescos, las profundidades religiosas, los pliegues introspectivos y los líos metafísicos. No conllevan el atrevimiento de Donne ni llenan el poema con imágenes personales y oscuras. Además, a diferencia de Sidney, Spenser o Shakespeare, estos nuevos poetas no aplican un lenguaje demasiado ornamentado, por eso no se concentran en la forma.

Ben Jonson es el inaugurador de la tradición a la que se suman otros poetas que se consideran como sus hijos literarios o la "tribu de Ben"11. El adalid de esta tendencia poética es representativo por el tratamiento de los temas, aunque no es el más ejemplar en cuanto al apego a los valores cortesanos porque su padre es un albañil que no puede 
ofrecerle un linaje como el que tienen algunos de sus seguidores. Su poesía comparte los valores clásicos en lo que atañe al tratamiento de los temas y en lo tocante a la cuidada forma y así lo manifiesta Jonson en Discoveries.

Los poemas de Jonson transmiten un toque de brevedad y espontaneidad. Su modo va cundiendo entre Robert Herrick o Thomas Carew quienes van haciendo el contenido más explícito desde el plano hedonista entonando canciones que resonarán, más adelante en otro puñado de poemas de tono libertino. La modulación es elegante, como postula Jonson en su arte poética "Still to be Neat" (1609) basado en el poema horaciano "Simplex Munditiis" donde bajo el símil de una señora que se acicala para ir a una fiesta, habla del arte desprovisto de tanto ornato y atuendo en búsqueda de la simplicidad. Por eso el arte de las composiciones de estos poetas es muy comprensible, alejado de la exuberancia y pirotecnia verbal de otros poetas.

La metáfora del vestido es retomada por Herrick en "Delight in Desorder" y condensada en el oxímoron del antepenúltimo verso (12), "a wild civility”, ya adelantado en el primer verso mediante el sintagma "sweet disorder”. El campo semántico de descuido late en muchos significantes (distraction, errin, neglectful, careless). El dulce desorden aquí descrito ofrece naturalidad, frente a la artificialidad, tanto en la vestimenta como en la obra de arte. La imperfección de la belleza, la de los poemas, es lo que hace brotar el placer estético. Este sendero metapoético se lee también en "Upon Julia's Clothes", del mismo autor. Hesperides es el libro de Herrick (1648) y en este poemario también sobresale un hablante explicando al lector que la belleza es como la rosa, un tiempo briosa y lozana pero, luego, se marchita. De ahí que aconseje el disfrute y el gozo antes de que el tiempo la vaya apocando, como leemos desde el comienzo de "To the Virgins, To Make Much of Time" (1-4): "Gather ye rosebuds while ye may".

De esta forma, el poeta ensaya el carpe diem quam minimum credula postero, el conocido tema acuñado por Horacio en Odas $(\mathrm{I}, 11)$. El seize the day preside el significado de muchos de sus poemas. No siguen una práctica literaria de forma sistemática; más bien escriben en los intervalos de la vida ${ }^{12}$ confiriendo un toque de estoicismo y epicureísmo. Con razón estos caballeros amigos de la música prefieren disfrutar el día, los placeres de la vida, la vita bona o la vita beata y celebrar la amistad, la felicidad interior y la hospitalidad. Así lo demuestra la conocida "Song. To Celia" que clama así en su primer verso: "Come, my Celia, let us prove". Andrew Marvell en su conocido "To His Coy Mistress" cultiva lo mismo. Los cuatro versos iniciales son suficientes para establecer el contexto y en cierto modo los dramatis personae, aludiendo de modo tangencial al macrotema del tiempo:

Had we but world enough, and time,

This coyness, lady, were no crime.

We would sit down and think which way

To walk, and pass our long love's day;

Marvell es un poeta lírico enigmático y difícil de clasificar porque en el tono coincide con Jonson mientras que por sus acabados es tan original como Donne en tanto que 
genera un hálito de privacidad y territorio íntimo cercano al de Emily Dickinson ${ }^{13}$. Ambos, Marvell y Dickinson prefieren no publicar su obra. El poeta no sigue el sendero de los Cavaliers, pues es un hombre de estado al servicio de Cromwell, de ahí que trabe amistad con Milton para el que ejerce como secretario, que después conseguirá su sillón como parlamentario durante los veinte últimos años de su vida. Coincidimos con Harold Bloom cuando afirma que las categorías amplias no cuadran con la herencia de Marvell.

Volvemos a Celia que también aparece en la obra de un caballero y cortesano de ingenio, Thomas Carew, que ve en letras de molde solamente una decena de poemas, pues la recopilación Poems sale de las prensas el año de su muerte (1640). Claro que él no parece interesado en publicar su obra; de hecho alcanza su brío en círculos reducidos. Su estilo coloquial, que en ocasiones está escrito en octosílabos como es el caso del poema de persuasión "To A. L.", la simpleza de la escritura así como su vitalidad configuran un legado apto para la difusión arropado por la fijación del clasicismo en la literatura inglesa. En efecto, Poems se edita el año de su fallecimiento, en 1640 y contiene poemas de amor como "Red and White Roses".

Este espíritu hedonista es el que cultivan otros componentes de la generación como Suckling y Lovelace. John Suckling, soldado y prototipo de caballero cortesano, consigue un efecto lírico más apegado a lo coloquial, incluso, que Carew. Richard Lovelace también es buen ejemplo de esta pléyade el cual publica en 1649 su serie Lucasta.

\section{La poesía religiosa: puritanismo y devoción}

La poesía sobre Dios y la religión es otro venero que alcanza una elevada altura en el siglo XVII. Incluso se sirve, en muchas ocasiones, del adorno meditado del verso metafísico y de su elaborado ingenio hasta tal punto que algunos estudiosos emparentan el verso metafísico con el poema devocional. Hemos de advertir, sin embargo, que no todas las composiciones metafísicas son religiosas e, igualmente, que no todos los poetas religiosos del XVII cultivan el verso conceptual de los metafísicos. Es el amor divino que presentan las obras de Henry King, Francis Quarles, George Herbert, Richard Crashaw, Henry Vaughan o Thomas Traherne. Indudablemente, el aspecto religioso de John Milton se arraiga en los poemas de Donne, Herbert, Crashaw o Vaughan. Esta corriente espiritual también descuella en otros países como Francia, Alemania o España.

Resulta elocuente el hecho de que Robert Herrick titule su libro de 1648, Hesperides, compuesto por más de mil poemas. A este se suma otro de tintes más cristianos, Noble Numbers. Lo mismo se aprecia en la obra que Mildmay Fane publica, en el mismo año, bajo el nombre Otia Sacra e incorpora más de un centenar de composiciones. El elemento religioso permanece en la cabecera de unas obras que están inaugurando el circuito impresor. A saber, los poetas que se atreven a publicar poesías no se desprenden del componente religioso elevándolo al pórtico de sus obras. En la obra de Herbert convive la temática sagrada, imbuida de tintes filosóficos, con la temática secular, tal como señalara Williamson ${ }^{14}$.

13 Bloom, H., The Best Poems of the English Language, New York, Harper Perennial, 2004, p. 170.

14 Williamson, G., supra note 8, p.94-117. 
Los escritores metafísicos componen un nutrido corpus de poesía religiosa (Matz, 1962: 20-30) como se aprecia en The Temple (1633, Herbert), Steps to the Temple (1646, Crashaw), o en Silex Scintillans (1650, del galés Vaughan) donde expone su moriendo, revixi. Los vericuetos metafísicos que cultiva Donne en su poesía religiosa los considera George Herbert excesivos y de ahí que abogue por un estilo más llano. Herbert muestra un tono de carácter íntimo que, por otra parte, refleja el aspecto más rural y familiar de sus feligreses en Wiltshire. The Temple, editado en 1633 por Nicholas Ferrar, transmite la sencillez del orador de origen galés y recorre, siguiendo la arquitectura de una iglesia, la vida de conversión desde la llegada al templo hasta la contemplación y comunión divinas. En esta obra se hallan poemas que plantean una conversión del verso inglés, al modo bautismal, hacia una llaneza que permita una comunicación clara con Dios y, como tal, sea compartida con el lector; así se ve en "Jordan I” de Herbert.

Por otra parte, Herbert modela algunos poemas con una marcada carga gráfica. Unos, como "Easter Wings" y "The Altar", concentran una figura que emula su significado (shaped poems), los cuales apuntan a la poesía visual. Incluso encierran un mensaje leyendo al sesgo, como "Colossians, III. 3. Our Life is Hid with Christ in God", cuyas palabras en mayúscula, leídas de arriba abajo, component una nueva oración plena de contenido semántico.

El foco temático que vemos en el libro de Herbert es retomado por Richard Crashaw en Steps to the Temple. En este caso estamos ante el poeta más europeo de los ingleses, por el estilo italiano y español que contienen sus versos. Su barroquismo se lee en poemas como "The Tear" donde describe, como si de perlas se tratara, las lágrimas de la Virgen María. Otro poema emblemático es "The Flaming Heart”, en este caso con más de un centenar de versos, que sigue de cerca las huellas de Santa Teresa de Jesús y describe lo inefable del arrebato místico que siente el escritor. La obra de Crashaw, en su conjunto, muestra una neta imaginería barroca realmente única en la historia de la literatura inglesa del siglo XVII.

En Crashaw, igual que en Donne, la religión convive con el amor porque el poeta publica por un lado obras como Epigrammatum Sacrorum Liber o Carmen Deo Nostro mientras que, por otro, compone The Delights of the Muses, que es difundida por un amigo de forma anónima cuando Crashaw se encuentra exiliado en Francia (1646). Esta doble vertiente la ostenta también Henry Vaughan en Olor Iscanus y en Silex Scintillans (1650) que abarca una alegoría de la conversión cristiana, brotada de su propia experiencia. La primera de las cuatro estrofas que componen "Mount of Olives" aboga por la comunión con Dios aludiendo tanto al lenguaje del amor y como al concepto metafísico.

Una diferente nota religiosa, con distinto eco, es la que eclosiona en el siglo siguiente con los acordes meditativos y prerrománticos de Blair, Gray o Hervey ambientados en el silencio del camposanto e inmersos en un tono meditativo, lúgubre y tétrico en ocasiones.

Otro faro de poesía religiosa, como antes se anotó, es John Milton, cuya herencia literaria se resiste a encasillarlo dentro de un grupo determinado. En este sendero religioso se insertan algunos poemas tempranos de Milton como son la oda sobre el nacimiento de Cristo, escrita en diciembre de 1629 y los poemas "The Passion" o "Upon the Circumcision". Milton está poetizando momentos religiosos estelares como la navidad o la crucifixión. Su faceta religiosa le lleva a colocar el poema sobre la natividad del Señor, 
"On the Morning of Christ Nativity", tras el pórtico del libro que publica en 1645, Poems of Mr. John Milton, both English and Latin.

Los puritanos escriben porque tienen un mensaje que consideran capaz de redimir al hombre. Para el escritor puritano la literatura es un camino salvífico. Así lo proclama Milton en el verso 26 del primer libro de Paradise Lost, "And justifie the wayes of God to men". La obra, empero, también porta un mensaje político ${ }^{15}$. De ahí que no sigan las huellas de la recreación artística metafísica secular ni el gozo que halla los poetas caballeros en sus composiciones amatorias paganas. "Libidinous and ignorant Poetasters" y "vulgar Amorist" son los calificativos que el puritano republicano vierte contra quienes no se dedican al cultivo del espíritu y del conocimiento. Por eso clausuran los teatros y de ahí que durante el experimento republicano merme el número de publicaciones poéticas.

\section{El verso libertino durante el reinado de Carlos II}

Las bases que sientan los poetas caballeros arrojan ahora unos frutos literarios. Un aristócrata con ingenio y talento literario es John Wilmot, conde de Rochester, nacido en una circunscripción de abolengo monárquico (Oxfordshire), hijo de un Cavalier y de una dama profundamente religiosa cuyas relaciones sociales tienen alto poder económico. $\mathrm{Su}$ vida es de leyenda, así lo piensa Etherege cuando lo convierte en el protagonista de una obra de teatro. Siguiendo los pasos del personaje Dorimant, aprendemos mucho sobre las andanzas de Rochester, que ve su vida truncada a los 33 años. Gilbert Burnet recoge en esta frase su entrega al alcohol y otros excesos: "for five years together he was continually drunk". Representa el grupo de los court wits, los ingenios de la corte, donde hemos de adscribir también a Dorset (Charles Sackville, conde de Dorset y Middlesex) y a Sedley.

Sirva como muestra el escenario que genera en el parque St. James, que ha sido denominado por Hammond como "pornotopia". El espíritu errante del personaje se traslada a la escritura de tal forma que el estudioso Raman Selden le denomina "rant" rochestereano ${ }^{16} \mathrm{y}$ así lo retoma Davis a propósito de las sátiras de John Oldham.

Rochester no piensa en el vulgo, no piensa en el lector, como hiciera el español Lope de Vega y como hacen Aphra Behn o John Dryden. El último fragmento de la décima sátira del primer libro de Horacio (115-124) plasma con meridiana claridad que sus guías no son los lectores; tampoco los críticos, sino sus amigos.

I loathe the rabble, 'tis enough for me

If Sedley, Shadwell, Sheppard, Wycherley,

Godolphin, Butler, Buckhurst, Buckingham,

And some few more, whom I omit to name,

Approve my sense: I count their censure fame.

15 Galván F., "Introducción” a J. Milton, El paraíso perdido. Madrid, Austral Summa, 2003, p. 52.

16 Selden, R., "Commonwealth and Restoration Satire”, English Verse Satire. 1590-1765, London, George Allen \& Unwin, 1978, 191. 
Ayudan a forjar el mito de Rochester las caracterizaciones que le otorgan no solo Etherege, sino también Aphra Behn, en The Rover, donde quiere deleitar al lector con la figura de Willmore, o Nataniel Lee cuyo The Princess of Cleves pone sobre las tablas del escenario a un tal conde de Rosidore cuyos modales y comportamientos recuerdan a John Wilmot.

Otras líneas de desarrollo de esta poesía están, como se ha asomado, en Etherege y Behn. El conde compone un "The Imperfect Enjoyment”, Etherege también escribe el deleite imperfecto mientras que en la temática de Aphra Behn tampoco podía faltar este asunto tan explícito y osado que detona la fama de Príamo.

La inseguridad, el escepticismo y el relativismo que encara la filosofía de vida del conde le lleva más directamente al cultivo del carpe diem. Pero no es todo libertinismo propiamente dicho adobado con una chispa amorosa y hedonista. Hay también un impulso gnoseológico que atraviesa por completo su obra. De hecho, en algunos de sus versos se objetiva la profundidad filosófica y la penetración psicológica de sus temas, los cuales versan sobre la libertad humana, el materialismo hobbesiano, el cuestionamiento de la razón o la comparación entre los seres humanos y los animales. La densidad del contenido y la indagación se adelanta a la vertiente filosófica que asoma Pope. En este sentido, pueden estudiarse los versos de la conocida "Satire against Reason and Mankind". El poeta, con lentes de pensador, está colocando la razón humana y el instinto animal $v i s-\grave{a}$-vis para terminar adelantándose a las profundidades que plantea Swift en Gulliver's Travels, a propósito de los Houyhnhnms. El verso postrero (225) del poema rochesteriano es suficiente para cotejar esta idea: Man differs more from man than man from beast.

A la saga libertina se adscriben, además, George Villiers y Charles Sackville, dos escritores en la cúspide de la jerarquía social; junto a Sir Charles Sedley, Sir William Wycherley más Sir George Etherege, que pertenecen a una aristocracia ubicada en un peldaño más bajo que los anteriores. Otros ingenios menores que pululan en este ambiente son Henry Killigrew, Henry Savile y Sir Fleetwood Shepherd. Parte de la nómina citada es incluida por Vivian de Sola Pinto (1965) en su clásico estudio en el que vincula a este grupo con una vida jovial, festiva y placentera lo rotula bajo el sintagma de Court Poets.

Sobre Rochester, Bernd Dietz (1989) en su estudio pionero del autor y su obra recorre todo el legado del poeta para señalar su modernidad. El profesor Dietz observa la integridad de la obra y la relación con otros prohombres. Rochester es el contrapunto de Dryden a la vez que contrasta con los puritanos Marvell, Milton o Bunyan. Mientras que Milton predica los caminos salvadores para la humanidad, cuando Bunyan traza el camino del peregrino, este aristócrata de talento se dedica a labrar los versos sobre el acto sexual y su encantamiento o a escribir sobre el nihilismo y las debilidades humanas.

\section{Un logro social y literario: la mujer escritora}

La londinense Katherine Philips es una primera ejemplificación de la mujer que consigue un cierto renombre literario a partir de su trabajo creativo. Es la hija de un comerciante, la cual se casará con un parlamentario galés. Katherine, desde su infancia, se relaciona con la poesía admirando el neoplatonismo y creando a su alrededor un grupo de amigas que comparte el entusiasmo por la poesía y el amor por la buena conversación. Sus 
miembros portan sobrenombres bucólicos. La misma Katherine es conocida por el apodo de Orinda y se va a convertir en emblema de la mujer escritora, en el modelo al que otras mujeres aspirarán, entre otras cosas porque sube al escenario la primera obra de autoría femenina (Pompée, 1663). Así, algunos críticos aluden a la escuela femenina de Orinda ${ }^{17}$. Para ver la consideración que le dispensan, pensemos que en el último tercio del siglo, Mary Pix, al hilo de una tragedia de Delariviere Manley, alude a los encantos de Safo y a la dulzura de Orinda (The Royal Mischief).

La tópica celebradora de la amistad femenina queda como muestra de su talento e incluso permite lecturas antitéticas según se aplique un criterio de amor platónico o de relación erótica ${ }^{18}$. Una buena muestra es el principio de una composición popular que venera su amor por Lucasia, cuyo título es literalmente "Orinda to Lucasia Parting October 1661 at London".

A pesar de la celebración del amor femenino, sus versos son pudorosos porque no trascienden del amor platónico quedándose en una relación más intelectual que carnal. De ahí que podamos nombrar a Aphra Behn como contrapunto vital y literario. Porque Behn no vacila en colocar a dos amantes en una arboleda mostrando sus intimidades abiertamente al lector, tal como se observa en "Dissapointment". Tampoco le tiembla el pulso al describir los deseos de una doncella cuya historia plantea su traslado con Amyntas hacia un locus amoenus retirado y alejado de la vista humana. Es aquí, en "The Willing Mistress" donde la escritora clama sutilmente por la igualdad de género concretamente a través de estos versos (13-16):

A many kisses he did give:

And I return'd the same

Which made me willing to receive

That which I dare not name.

La poeta proviene de una familia de Canterbury, su madre es una nodriza y su padre un barbero, gracias a los cuales se relaciona con la familia Culpepper, donde la joven inquieta leería en la biblioteca de estos señores de Kent llegando también a aprender varias lenguas modernas debido al trasiego de visitantes que moran en la ciudad del sur. También se sugiere que debido a su catolicismo pudo formarse en un convento ${ }^{19}$ lo que explica el acervo humanístico de la escritora. Visita Suriman cuya imagen será plasmada en su relato Oroonoko or the Royal Slave. Más adelante viaja como espía a Amberes.

Luego se lamenta por carecer de una educación formal y, principalmente, por desconocer las lenguas latina y griega, en las que de modo autodidacta va adentrándose. Aphra Behn sufre la bancarrota durante el tiempo en que Dryden es nombrado Poeta Laureado, viéndose en bastantes apuros económicos. El rey olvida enviarle el prometido

17 Andreadis, H., “The Sapphic-Platonics of Katherine Philips, 1632-1664”, Signs: Journal of Women in Culture and Society, 1989, vol. 15, p.34

18 Menges, H., "Authorship, Friendship, and Forms of Publication in Katherine Philips", Studies in English Literature, 1500-1900, Vol. 52, № 3, 2012, p.517.

19 Damrosch, D., "Aphra Behn", The Longman Anthology of British Literature, Nueva York, Pearson Education, 2004, p. 1114. 
apoyo económico; así se lee en las cartas enviadas desde Bélgica. En la dedicatoria al lector de Sir Patient Fancy (1678) sienta las bases de su singladura cuando escribe que ella estaba "forced to write for bread and not ashamed to owne it". Se entiende que aplique la brega social por ascender ${ }^{20}$, incluso se puede afirmar que su precaria situación económica es la causa definitiva que le empuja para convertirse en escritora profesional, una decisión atrevida, sorprendente y revolucionaria en su momento.

Su situación personal, además del legítimo deseo de querer obtener unos ingresos con su trabajo literario que le permitan vivir, le lleva a producir obras de teatro. La tragicomedia The Forced Marriage abre su camino dramático, en 1670, cuando la obra es representada en Linconl's Inn Fields, manteniéndose en cartel seis jornadas; tras la cual irá dando a la escena y a la imprenta otros trabajos como la famosa comedia de costumbres The Town-Fop o la comedia de intriga The Rover que en una conocida edición española ha sido traducida como El aventurero. En lo que atañe a la poesía, hay que citar Covent Garden Drolery que ve la luz en 1672, siguiéndole en la segunda mitad de los años 80 las obras tituladas Poems upon Several Ocassions, Miscellany y Lycidus. Una lectura a fondo de sus versos denota el inconformismo de la autora que subvierte la temática y los roles de los personajes en aras de posicionar a la mujer en un lugar mejor.

Hacia noviembre de 1682 la demanda teatral decae sobremanera. Por este tiempo un escándalo ocurrido en Londres da la pista argumental a la escritora para relatarlo. Se trata de un caso de incesto ocurrido en la clase social alta. Henrietta Berkeley se fuga con su amante Lord Grey. Resulta ser la hija de un conocido tory. El amante es un whig. Al entramado del amor, se le suma el político. Entretanto, la hermana de Henrietta también mantiene una relación con el duque de Monmouth. Lord Grey y el duque comparten amistad y afinidad política. Grey escapa; de lo contrario, habría sido juzgado por traición. De aquí emana Love-Letters Between a Nobleman and his Sister. La acogida del público fue buena; por eso amplía la idea con dos volúmenes más, por lo que la obra global se publica desde 1684 hasta 1687.

La disminución de las representaciones cuando muere Carlos II le impele a cambiar de género literario. Aquí estriba una razón de su dedicación a la narrativa cuya obra más conocida es Oroonoko or the Royal Slave que es publicada el año del nacimiento de Alexander Pope, a la vez que lanza al naciente mercado editorial otros trabajos como la narración The Fair Jilt, or the History of the Prince Tarquin o la traducción The History of Agnès de Castro or the Force of Generous Love, un romance francés que se ajusta con fidelidad al original.

1688, desde el punto de vista socio-político es el año de la Revolución Gloriosa. Según ha estudiado Steve Pincus (2009) es el año de La primera revolución moderna. La batalla de Boyne (1 de julio de 1690) supone el golpe final a Jacobo II y eleva los ánimos de los Protestantes de Ulster que ven su causa como gloriosa, victoriosa. Según se ha indicado, ahora reluce un hecho literario reseñable que es la publicación del librito de Aphra Behn. Oroonoko, or the Royal Slave no nace ajeno a los avatares históricos que lo contextualizan y lo singularizan. La obra del esclavo real es un arma arrojadiza contra el bando whig y

20 Duffy, M., The Passionate Shepherdess: Aphra Behn, 1640-1689, London, Jonathan Cape, 1977; Goreau, A., Reconstructing Aphra: A Social Biography of Aphra Behn, New York, Dial Press, 1980; Todd, J., The Secret Life of Aphra Behn, London, André Deutsch Limited, 1996. 
contra el puritanismo finisecular. Es, a la vez, un arma defensiva del poder de los tory. Oroonoko es un asidero que se aferra a la dinastía Estuardo de la que James II será su último bastión. Finalmente la escritora se congratula en un poema por la coronación de María, destacando la belleza y el ingenio. Alaba solamente a la reina. La pieza se titula "A Congratulatory Poem" y señala el comienzo de un nuevo tiempo.

Al poco tiempo escribe The Nun; or, The Perjured Beauty cuya taracea argumental se centra en la carnavalización de las identidades y en las intrigas amorosas igual que se aprecia en The Lucky Mistake o en la nombrada comedia de costumbres The Lucky Chance. Dedicarse a la literatura como profesión en pleno siglo XVII significa ser una mujer pública poniendo a la venta su trabajo lo cual recuerda al ejercicio de la prostitución. La valentía y el empeño de Behn hacen que Virginia Woolf, en A Room of One's Own establezca el valor propulsor en lo que concierne a los derechos de la mujer. Precisamente el hecho de que Aphra Behn yazca en el rincón de los poetas de la abadía de Westminster, junto a las otras tallas literarias de Johnson, Dickens o Kipling no viene sino a confirmar la meritoria labor de la escritora que profesionaliza la literatura retando los dogmas de una sociedad eminentemente patriarcal, así como su independencia, su rebeldía y su singularidad.

Otra voz digna de estudio, en contraposición, es Margaret Cavendish. El nexo de unión que vincula a ambas estriba en que las dos defienden a la mujer, cada una desde su posición en la sociedad. Margaret Cavendish publica sus Poems and Fancies en 1653, generando a partir de este año catorce libros sobre temas que van desde las mariposas a los átomos. Virginia Woolf ${ }^{21}$ comienza su trabajo sobre Margaret Cavendish con estas palabras, tomadas de la obra de la propia escritora: "All I desire is fame". Kathleen Jones ${ }^{22}$ titula su trabajo precisamente como Glorious Fame: The Life of Margaret Cavendish, Duchess of Newcastle 1623-1673. Este reconocimiento permite aducir un hecho insólito en su momento y pionero en la historia de la literatura que no es otro que una mujer buscando renombre y medro en el panorama creativo del siglo XVII.

Cavendish, durante su exilio francés, participa en La Tétrade donde se reúnen pensadores y eruditos del momento. Su hermano Sir Charles Cavendish, congrega en Francia a científicos y a filósofos a los que la flamante escritora tiene, por tanto, un fácil acceso. Es el denominado Círculo de Newcastle en París. Su apego a las matemáticas y otras ciencias destila en poemas como "The Arithmetic of Passions". La poeta es consciente de su trabajo y es sabedora de su vocación ${ }^{23}$. Por otra parte, el entramado de sus Philosophical Letters muestra un esfuerzo inaudito para subvertir los patrones epistemológicos y culturales de la sociedad ${ }^{24}$.

21 Woolf, V., The Common Reader, London, Pelican Books, 2012, p.78.

22 Jones, K., A Glorious Fame: The Life of Margaret Cavendish, Duchess of Newcastle 1623-1673, London, Bloomsbury, 1988.

23 Scott-Douglas, A., "Self-Crowned Laureatesses: the Examples of Margaret Cavendish and Jane Lead", en Cuder-Domínguez, P., et aliis (ed.), The Female Wits. Women and Gender in Restoration Lietrature and Culture, Huelva: Servicio de Publicaciones de la Universidad de Huelva, 2006, 65.

24 Walters, L., “Cavendish's Letters of Subversion", en Cuder-Domínguez, P., et aliis (ed.), The Female Wits. Women and Gender in Restoration Lietrature and Culture, Huelva: Servicio de Publicaciones de la Universidad de Huelva, 2006, 282. 
La aportación de Cavendish a la historia de la literatura inglesa es relevante. Desde sus posiciones aristocráticas, aboga por la igualdad y reclama un lugar justo para la escritora así como una consideración que esté a la misma altura que el escritor. Una vez que rompe las barreras que asedian a las mujeres que desean publicar su poesía, pone en primer plano su deseo de fama aplicando los mecanismos de quienes se consideran poetas y no ocultan su identidad. Este anhelo de posteridad se lee en "The Poetresses Petition" o en "An Apology for Writing So Much upon This Book” donde declara su vocación.

Es lo que Helgerson denomina "women poet-prophet" y lo que Amy Scott-Douglas ${ }^{25}$ decide llamar "self-crowned laureatesses". Las transgresiones tienen que ver con las cuestiones del género y el estatus social. Su lucha por una igualdad que en aquel tiempo es una utopía es notoria así como la integración de la observación, la filosofía, la filosofía natural (física) e incluso una suerte de ciencia ficción. No en vano, es la primera mujer miembro de la Royal Society.

Una sociedad literaria hostil respecto a la escritura poética femenina requiere justificaciones y reprimendas por parte de las poetas, como regla general. La poeta que decide publicar sus versos (en palabras de Killigrew: "Embolden'd this, to Fame I did commit") persigue los mismos deseos que el escritor que entrega sus frutos a un editor. Lo que pasa es que la mujer utiliza los mismos mecanismos y ardides creativos que el hombre. Con todo, no siempre logra sus objetivos, como predica el poema de Anne Killigrew titulado "Upon the Saying that My Verses were made by Another".

Estamos ante la misma poeta que en su primer poema "Alexandreis" invoca a la musa en su plegaria rogándole su favor, a través de un poema épico que se desmarca del molde habitualmente circunscrito a la mujer que es de carácter más liviano y sobre temas más ligeros como es el caso de la amistad que adoba Philips. Es valiente al hacer uso de un género grave, generalmente reservado para el varón. Después de la inspiración, hay ejércitos tras los que tiene lugar la batalla; y con esto también podemos decir que hay bravura por parte de Killigrew porque está tratando de conquistar un territorio literario utilizado para las creaciones de los poetas.

Son muchas las poetas en las que habría que reparar para hacer una secuenciación justa, desde la pionera Mary Wroth, la primera mujer que publica una obra en prosa y una secuencia de sonetos, junto a los nombres de Anne Bradstreet, Anne Marchioness Wharton, Jane Barker y Anne Finch hasta otra nómina que abarca el siglo XVIII.

\section{Paisaje y política: Los poemas "Country-house"}

Hay otra tradición de aspecto secular, la política. Los trasuntos de estado y de sociedad están presentes en la literatura del siglo XVII, que como se viene observando es poliédrica en lo que a temática se refiere. A esta vertiente política se circunscriben la mayoría de las

25 Scott-Douglas, A., "Self-Crowned Laureatesses: the Examples of Margaret Cavendish and Jane Lead", en Cuder-Domínguez, P., et aliis (ed.), The Female Wits. Women and Gender in Restoration Lietrature and Culture, Huelva: Servicio de Publicaciones de la Universidad de Huelva, 2006, 66 . 
estrofas de Dryden. Incluso hay una poesía sobre el lugar que entrevera temas sociales. La topográfica es, por tanto, un tipo de poesía que describe el paisaje y que se fusiona en un nivel secundario de significado con los asuntos políticos y personales.

Ahondamos en este epígrafe en un género que se escinde a su vez en dos tipologías según alaben a una persona de la sociedad o simplemente se centren en el paisaje. Los bautizados como "country-house poems" ${ }^{26}$ son los que, sin dejar de lado el paisaje, acercan el foco a una figura social acaudalada adulándola y lisonjeándola, mientras que los "prospect poems" utilizan el locus, que puede ser también un jardín, para realizar una reflexión histórica o más secundaria tratándola como tal, alejada del momento presente.

En 1611 Aemilia Lanyer difunde su "Description of Cookham" como una pieza de acompañamiento al poema Salve Deus Rex Judaeorum. Los versos de la descripción alaban a la condesa de Cumberland y ensalzan la villa rural en Berkshire como lugar de encuentro para las literatas. El mismo procedimiento del elogio lo encontramos en los poemas de Jonson “To Sir Robert Wroth" y "To Penhurst”, publicados en The Forest, en 1616. Los 102 versos que componen “To Penhurst” están, por una parte, enalteciendo al propietario Robert Sidney (primer conde de Leicester, hermano del poeta Sir Philip Sidney) y, por otra, están regocijándose en la descripción de Penshurst:

Thou art not, Penshurt, built to envious show

Of touch or marble; not canst boast a row

Of polish'd pillars, or a roof of gold:

Thou hast no lantern whereof tales are told;

Or stair, or courts; but stand'st an ancient pile,

And these grudg'd at, art reverenced the while.

A este tipo de poesía, siguiendo el lenguaje latino, se le puede denominar "locodescriptiva" porque describe un emplazamiento determinado, aunque este rótulo no comunica el contenido integral de la misma. El poeta Carew realza la vida campestre en "To Saxham", a la vez que encomia a la familia Crofts. Quien venga a este lugar de Suffolk purificará su vida, según el citado poema, compuesto en la década de 1620. Otra muestra del cultivo del género es el poema que dedica a un amigo, cuando ha visitado Escocia; “To my friend, G. N. from Wrest" (1640) presenta remanso de paz frente a la Guerra de los Obispos (Bishops' War, Bellum Episcopale).

De 1648 data el panegírico que Robert Herrick dedica a Sir Lewis Pemberton como agradecimiento a su generosidad y a su carácter hospitalario. El poema se titula "A Panegyric to Sir Lewis Pemberton" y su destinatario es un administrador de justicia proveniente de la familia Lancanshire, nacido al sur de la comarca de Hertfordshire. El siguiente trabajo de obligada referencia también está dedicado a una persona del mundo político y militar, en este caso el célebre general Fairfax conocido también como Tom el Negro. 
El parlamentario que naciera en Yorkshire Andrew Marvell es, de esta forma, otro escritor que unimos a este grupo, concretamente por sus aportaciones "Upon the Hill and Grove at Billborow" y el magno poema "Upon Appleton House", el dedicado a Fairfax. Esta composición tiene numerosas estrofas y data de 1651. El cronotopus se ubica en lo que fuera un Monasterio cisteriense (Nunappleton) antes de que Enrique VIII los suprimiera. En el momento de la redacción del poema el espacio es una hacienda de Lord Thomas Fairfax de Cameron, donde Marvell acude para trabajar como tutor de la hija del general republicano entre 1650 y 1652. La escritura de Marvell se detiene en las estrofas centrales en los jardines y la flora del recinto para presentar los riachuelos y el bosque habiendo al principio detallado el estilo arquitectónico de la construcción:
Within this sober Frame expect
Work of no Forrain Architect;
That unto Caves the Quarries drew,
And Forrests did not Pastures hew;
Who of his great Design in pain
Did for a Model vault his Brain,
Whose Columnes should so high be rais'd
To arch the Brows that on them gaz'd.

La característica de este poema es que a través de las vistas delineadas integra una visión propia sobre los asuntos políticos, sociales o religiosos, como se coteja en la estrofa quinta, explicitando incluso el nombre de su señor, quien muestra su hospitalidad y generosidad con el joven poeta:
And surely when the after Age
Shall hither come in Pilgrimage,
These sacred Placed to adore,
By Vere and Fairfax trod before,
Men will dispute how their Extent
Within such dwarfish Confines went:
And some will smile at this, as well
As Romulus his Bee-like Cell.

El escritor de origen dublinés John Denham es otro poeta impulsor del género, con Cooper's Hill (1655). El poema se acerca a los lugares aledaños a la casa del poeta en Egham (Surrey) y diseña una excursión por el río Támesis con detenciones en Windsor Castle, las ruinas de Chertsey Abbey, en los márgenes fluviales de Runnymede. Los temas políticos adobados por el retiro rural y los edificios colindantes dan pie al autor para cargar la semántica de resonancias políticas como se lee en las referencias a la catedral de San Pablo que introduce la cuestión religiosa, la correlación entre el declive y las cenizas que deja el fuego, la ciudad y el asunto económico, la realeza y la sociedad. La invectiva que confiere Denham en la semiología del poema es quizá uno de sus aspectos más originales. 
Un poeta coetáneo de Denham es Waller que compone “On St. James’s Park” (1660) el cual ofrece sus loas oportunas a la monarquía deteniéndose en detalles paisajísticos que permiten que lo incluyamos en este apartado. Pero no toda la literatura política es acorde con los tiempos. Por ejemplo, Parnassi Puerperium de Thomas Pecke se publica en 1659 y su primer poema está dedicado a Richard Cromwell, el hijo y continuador durante un año de Oliver Cromwell. Hay otro puñado de versos que ensalzan a algunas conocidas figuras parlamentarias. Sin embargo, tras la República, la Monarquía se establece en 1660 y este poemario no recoge muchas prebendas desde la esfera del poder.

En el siglo XVIII (en 1713 y de la mano de Pope) encontramos Windsor Forest, un poema de ascendencia virgiliana que elogia la Paz de Utrecht a la vez que transfiere los parabienes a la vida feliz del agro (la tranquilidad, la pesca, la caza) sublimando la naturaleza en derredor como es el caso del reflejo de los ríos y la potenciación del componente local. Se concitan aquí las Geórgicas de Virgilio con el beatus ille. El bosque de Windsor es el eslabón que une la poesía paisajística que surge en el siglo anterior con los venideros poemas de paisaje. Un caso es The Deserted Village del irlandés Oliver Goldsmith y así lo vemos resurgir con los románticos y su amor por las estampas paisajísticas.

\section{Conclusiones}

En el terreno práctico, England Parnassus es una referencia poética a comienzos del siglo XVII. En el campo teórico George Puttenham publica The Art of Englishe Poesie (1589); estudia la retórica así como el comportamiento del buen cortesano. En 1583 A Defense of Poesie sale de las prensas, a manos de Sir Philip Sidney, defendiendo la ontología de la poesía, como la pintura, así como el deleite y la didáctica que transmite. El contraste entre los postulados incluidos en las obras anteriores respecto a la evolución de la poesía durante el siglo XVII pone de manifiesto que el siglo de Donne, Jonson, Milton, Rochester, Behn y Dryden se distancia de la tradición renacentista para inaugurar una nueva etapa en la historia de la literatura inglesa.

Las misceláneas de poesía ayudan a hacerse una composición de lugar sobre el estado de la literatura en una época determinada. El medio millar de páginas que componen Englands Parnassus, recopilado por Robert Allot hacia 1600, y editado por Charles Crawford, es buen escaparate del estado de la poesía a comienzos de siglo, mostrando un retrato de la lírica en un tiempo determinado. Otra publicación, en este caso la mitad de voluminosa que la anterior es Englands Helicon, al cuidado de Hugh MacDonald. También data del primer año del siglo. Los nombres bucólicos en el tomo asoman el ambiente pastoril que se respira a través de sus páginas.

Un vistazo a estos libros recopilatorios y otra mirada a la poesía del siglo XVII permite marcar las diferencias entre el pasado y el presente. Los poemas de las dos misceláneas se pueblan con Ninfas junto a los familiares nombres de Diana, Astrophill, Phillis, Coridon, Febo, Amarillis, Chloris, Damelus, Diaphenia, Aminta, Cinthia, Daphne, Taurisius, Clorinda, Sylvanus, Arsilius, Polydora, Stella, etc. La estética renacentista e isabelina late en estas páginas donde el diálogo pastoril y el soneto son dos modos emblemáticos de esta tradición a la que suplantarán dos nuevas escuelas literarias que lucen a principios del siglo XVII (la metafísica -Donne- y la de los caballeros -Jonson, Herrick-). 
Desde finales del siglo XVI se observa cómo muchos escritores optan por la lengua vernácula para componer poesía. A saber, prefieren el inglés al latín. Buscan una forma más natural y más cercana en los temas que la aplicada por Chaucer, Skelton, Heywood o Wyatt. Durante el siglo XVII la vida literaria de Londres amplía sus cauces. Comienzan a desarrollarse nuevos circuitos literarios. La esfera pública expande su radio. Antes de esta expansión perviven otras formas literarias, como es el caso de autores de carácter cortesano que se congregan en torno al palacio de Whitehall, o la prolongación isabelina que contiene la obra de otros escritores. También surge un apetito de lectura inaudito hasta el momento.

En los últimos años del siglo se publican varias ediciones misceláneas de poesía. La figura del mecenas irá dejando paso a las figuras del librero y del editor. El poeta aficionado o diletante señala el fin de una época y el comienzo de otra donde el poeta profesional va señalando el nuevo panorama.

\section{Literature}

Alexander, M., A History of English Literature. New York, Palgrave Macmillan, 2007 ( $2^{\text {nd }}$ edition).

Alsop, D., "Literature 1660-1714", en A. Chantler \& D. Higgins (eds.), Studying English Literature. London, Continuum, 2010.

Andreadis, H., "The Sapphic-Platonics of Katherine Philips, 1632-1664", Signs: Journal of Women in Culture and Society, 1989, vol. 15.

Ballesteros González, A., J. A. Hormigón, "Introducción" a El exiliado, Madrid, Asociación de Directores de Escena, 2003.

Baynes, Coiro, A, “The Personal Rule of Poets. Cavalier Poetry and the English Revolution", en The Oxford Handbook of Literature and the English Revolution, Oxford, Oxford University Press, 2012.

Blackley, B. \& L. M. Crowley, "Literary and Cultural Contexts", en R. C. Evans \& E. J. Sterling (eds.), The SeventeenthCentury Literature Handbook. London, Continuum, 2010.

Bordieu, P., Las reglas del arte: génesis $y$ estructura del campo literario, traducción de Thomas Kauff, Barcelona, Anagrama, 1995.
Bloom, H., John Milton, New York, Chelsea House, 1986.

Bloom, H., Genius. A Mosaic of One Hundred Exemplary Creative Minds, New York, Warner Books, 2002.

Bloom, H., The Best Poems of the English Language, New York, Harper Perennial, 2004.

Bloom, H., The Anatomy of Influence. Literature as a Way of Life. Yale, Yale University Press, 2011.

Brower, R. A., Alexander Pope: The Poetry of Allusion, Oxford, Clarendon Press, 1963 (1959).

Burke, P. \& R. Po-Chia Hsia (eds.), Cultural Translation in Modern Europe. Cambridge, Cambridge University Press, 2007.

Chantler A. \& D. Higgins (eds.), Studying English Literature. London, Continuum, 2010.

Chico, T., "The Arts of Beauty: Women's Cosmetics and Pope's Ekphrasis" ", Designing Women. The Dressing Room in Eighteenth-Century English Literature and Culture, Lewisburg, Bucknell University Press, 2005.

Coperías Aguilar, M. J., "Introducción" a A. Behn El aventurero, Madrid, Cátedra, 2006. 
Cros, E., Théorie et pratique sociocritiques, Montpellier, C.E.R.S. (1983) 1997.

Cros, E., La sociocritique, Paris, L'Harmattan, 2003.

Cuder-Domínguez, P., et aliis (ed.), The Female Wits. Women and Gender in Restoration Lietrature and Culture, Huelva: Servicio de Publicaciones de la Universidad de Huelva, 2006.

Cummings, R., (ed.), Seventeenth-Century Poetry. An Annotated Anthology. Oxford, Blackwell Publishers, 2000.

Damrosch, D., "Aphra Behn”, The Longman Anthology of British Literature, Nueva York, Pearson Education, 2004.

Davis, P., Translation and the Poet's Life. The Ethics of Translating in English Culture, 1646-1726. Oxford, Oxford University Press, 2008.

Davis, P., "Dryden and the Bounds of Liberty", in Translation and the Poet's Life. The Ethics of Translating in English Culture, 1646-1726, Oxford, Oxford University Press, 2008.

Dietz, B., "Los epigramas de Ben Jonson", in S. Onega (ed.), Estudios Literarios Ingleses: Renacimiento y Barroco, Madrid, Cátedra, 1986.

Dietz, B., (ed.), Estudios literarios ingleses: La Restauración (1660-1700), Madrid, Cátedra, 1986.

Dietz, B., "El siglo XVII", en C. Pérez Gallego (ed.), Historia de la Literatura Inglesa I. Madrid, Taurus, 1988.

Dietz, B., "La sociedad literaria de la Restauración. El contexto ideológico", en El progreso del libertino. La poesía de John Wilmot, Earl of Rochester, Secretariado de Publicaciones de la Universidad de La Laguna, 1989.

Dryden, J., The Satires of Dryden, J. Churton Collins (ed.). London, Macmillan, 1950.

Dryden, J., The Poems of John Dryden, P. Hammond, J. Barnard \& D. Hopkins (eds.), London, Longman, 2005.
Duffy, M., The Passionate Shepherdess: Aphra Behn, 1640-1689, London, Jonathan Cape, 1977.

Eliot, T. S., The Varieties of Metaphysical Poetry, New York, Harvest, 1993.

Eliot, T. S., "Ben Jonson", The Sacred Wood. Essays on Poetry and Criticism, London, Faber and Faber, (1920), 1997.

Elsky, M., "Milton", C. Woodring \& J. Shapiro (eds.), The Columbia History of British Poetry, New York, Columbia University Press, 1994.

Evans R. C., \& E. J. Sterling, The Seventeenth-century Literature Handbook, London, Continuum, 2010.

Farley-Hills, D., The Benevolence of Laughter. Comic Poetry of the Commonwealth and Restoration, London, Macmillan, 1974.

Fish, S., Versions of Antihumanism. Milton and Others. Cambridge, Cambridge University Press, 2012.

Galván, F., "Entre el lirismo y la sátira: la presencia de Horacio en la poesía inglesa moderna", Myrtia, 9, 1994.

Galván F., "Introducción" a J. Milton, El paraíso perdido. Madrid, Austral Summa, 2003.

Garrison, J. D., Dryden and the Tradition of Panegyric. Berkeley, University of California Press, 1975.

Goreau, A., Reconstructing Aphra: A Social Biography of Aphra Behn, New York, Dial Press, 1980.

Greenblatt, S., Renaissance SelfFashioning. From More to Shakespeare, Chicago, University of Chicago Press, 1980.

Hall, R. F., "Miltons's sonnets and his contemporaries", D. Danielson (ed.), The Cambridge Companion to Milton, Cambridge, Cambridge University Press, 1999.

Hammond B., "London and poetry to 1750 ”, en L. Manley (ed.), The Cambridge Companion to the Literature of London, Cambridge, Cambridge University Press, 2011. 
Hammond, P., John Dryden: A Literary Life, London, Macmillan, 1991.

Harp, R., "Historical Contexts" in R. C. Evans \& E, J. Sterling (eds.) The Seventeenth-Century Handbook, London, Continuum, 2010.

Hermann, P. C., A Short History of Early Modern England. British Literature in Context. Oxford, Willey-Blackwell, 2011.

Howard, J. E., "London and the early modern stage", en L. Manley (ed.), The Cambridge Companion to the Literature of London, Cambridge, Cambridge University Press, 2011.

Hughes, D., "Aphra Behn and the Uses of History”, in Cuder-Domínguez, P. et aliis (ed.), The Female Wits. Women and Gender in Restoration Lietrature and Culture, Huelva: Servicio de Publicaciones de la Universidad de Huelva, 2006.

Jiménez Heffernan, J., "John Donne and the New Science: Re-taking the Issue", Sederi, 8, 1998.

Jiménez Heffernan, J., La palabra emplazada: Meditación y contemplación de Herbert a Valente, Córdoba, Servicio de Publicaciones de la Universidad de Córdoba, 1998.

Johns, A., "London and the early modern book", in L. Manley (ed), Literature of London, Cambridge, Cambridge University Press, 2011.

Johnson, S., The Lives of the Poets, Oxford, Oxford University Press, 2009

Johnson, S., Selected Writings. A Tercentenary Celebration, Cambridge, The Belknap Press of Harvard University Press, 2011.

Jones, K., A Glorious Fame: The Life of Margaret Cavendish, Duchess of Newcastle 1623-1673, London, Bloomsbury.

Keegan, B., A. Haschenburger, "Questioning Canonicity" en G. Day
\& B. Keegan (eds.), The Eighteenth Century Literature Handbook, 2009.

Kempton, A., Survey of English Literature. From the Restoration to PreRomanticism, Bristol, Dunop, 1992.

Lauden, H., "Ladies of the Shade: The Pastoral Poetry of APhra Behn and Elizabeth Singer Rowe"., in P. Cuder-Domínguez et aliis (ed.), The Female Wits. Women and Gender in Restoration Lietrature and Culture, Huelva: Servicio de Publicaciones de la Universidad de Huelva, 2006.

Lewalski, B. K., "The genres of Paradise Lost”, D. Danielson (ed.), The Cambridge Companion to Milton, Cambridge, Cambridge University Press, 1999.

Lewis, C. S., "Golden”. I "Sidney and Spenser", in B. Dobree, N. Davis \& F.P. Wilson (eds.) English Literature in the Sixteenth century Excluding Drama (The Oxford History of English Literature), Oxford, Oxford University Press, 1954.

Lipking, L., "Jonson on Shakespeare" en The Life of the Poet, The University of Chicago Press, 1981.

Love, H., "Rochester and the Traditions of Satire", in Restoration Literature. Critical Approaches, London, Methuen, 1972.

Marotti, A. F., "John Donne and the Rewards of Patronage" en Lytle G. F. \& S. Orgel (eds.), Patronage in the Renaissance, Princeton, Princeton University Press, 1981.

Marotti, A. F. \& M. Freiman, “The English sonnet in manuscript, print and mass media”, in A. D. Cousins \& P. Howarth, The Cambridge Companion to The Sonnet, Cambridge, Cambridge University Press, 2011.

Martz, Louis L. The Poetry of Meditation: A Study in English Religious Literature of 
the Seventeenth Century, New Haven: Yale University Press, 1962.

McClung, W. A. The Country House Tradition in English Renaissance Poetry, Berkeley and Los Angeles, University of California Press, 1977.

McLaverty, J., Pope, Print and Meaning, Oxford, Oxford University Press, 2001.

Menges, H., "Authorship, Friendship, and Forms of Publication in Katherine Philips", Studies in English Literature, 1500-1900, Vol. 52, No 3, 2012.

Messenger, A., “Aphra Behn”, en Pastoral Tradition and the Female Talent. Studies in Augustan Poetry, New York, AMS Press, 2001.

Miner, E., "The Social Mode", The Cavalier Mode from Jonson to Cotton, Princeton, Princeton University Press, 1971.

Morgan, K. O., The Oxford Illustrated History of Britain, Oxford, Oxford University Press, 2009.

Morrissey, L., "The Restoration and eighteenth century, 1660-1780", en P. Poplawski (ed.), English Literature in Context. Cambridge, Cambridge University Press, 2008.

Newton, R. C., "Jonson and the (Re-) Invention of the Book", C. J. Summers \& T-L Pebworth (eds.), Classic and Cavalier. Essays on Jonson and the Sons of Ben, London, University of Pittsburgh Press, 1982.

Parry, G., Seventeenth-Century Poetry: the Social Context. London, Hutchinson, 1985.

Parry, G., "Robert Herrick and the ceremonies of innocence", in Seventeenth-Century Poetry: the Social Context. London, Hutchinson, 1985.

Partridge, A. C., "Introduction", in The Tribe of Ben, London, 1966.

Pincus, S., 1688: The First Modern Revolution, Yale, Yale University Press, 2009.
Poplawski, P. (ed.), English Literature in Context. Cambridge, Cambridge University Press, 2008.

Ribes, P., "Introducción” a J. Donne, Canciones y sonetos. Madrid, Cátedra, 1996.

Roche, T. P., "Shakespeare and the Sonnet Sequence" in C. Ricks (ed). English Poetry and Prose, 1540-1674. The Penguin History of English Literature. Vol 2, Harmondsworth, Penguin, 1970. Ruiz Pérez, P., El siglo del arte nuevo. 15981691, Madrid, Crítica, 2010.

Scott-Douglas, A., "Self-Crowned Laureatesses: the Examples of Margaret Cavendish and Jane Lead", en CuderDomínguez, P., et aliis (ed.), The Female Wits. Women and Gender in Restoration Lietrature and Culture, Huelva: Servicio de Publicaciones de la Universidad de Huelva, 2006.

Selden, R., "Commonwealth and Restoration Satire", English Verse Satire. 1590-1765, London, George Allen \& Unwin, 1978.

Sell, J. P. A., Conocer a William Shakespeare, Madrid, Laberinto, 2012

Skelton, R., "Cavalier Poets: Introduction”, in Cavalier Poets, London, Longman, 1960.

Sola Pinto, V. d., The Restoration Court Poets, London, Longman, 1965.

Spiller, M. R. G., "The Sonnet and its Space" in The Development of the Sonnet. An Introduction, London \& New York, Routledge, 1992.

Terry, R., "Key Critical Concepts and Topics”, en G. Day \& B. Keegan (eds.), The Eighteenth-Century Literature Handbook. London, Continuun, 2009.

Tillyard, E. M. W., The Elizabethan World Picture, London, Penguin/Chatto and Windus, 1943.

Todd, J., The Secret Life of Aphra Behn, London, André Deutsch Limited, 1996. 
Tuve, R., Elizabethan and Metaphysical Imagery, Chicago, University of Chicago Press, 1947.

Walters, L., "Cavendish's Letters of Subversion", en Cuder-Domínguez, P., et aliis (ed.), The Female Wits. Women and Gender in Restoration Lietrature and Culture, Huelva: Servicio de Publicaciones de la Universidad de Huelva, 2006.

Watson G., "The Language of the Metaphysicals" in G. Watson (ed.), Literary English since Shakespeare, Oxford, Oxford University Press, 1970, 156-174.
Williamson, G., "The Context of Metaphysical Wit”, A Reader's Guide to the Metaphysical Poets, London, Thames \& Hudson, 1968, 11-25.

Woolf, V., The Common Reader, London, Pelican Books, 2012.

Woolf, V., A Room of One's Own, Londres, Penguin, (1929) 2004.

Zwicker, S. N. (ed.), The Cambridge Companion to John Dryden, Cambridge, Cambridge University Press, 2004.

\title{
WE'LL BUILD IN SONNETS PRETTY ROOMS: REVISITING SEVENTEENTH-CENTURY ENGLISH POETRY
}

\author{
Juan de Dios Torralbo Caballero \\ University of Cordoba, Spain
}

Summary. The interdependence between society and literature is an obvious phenomenon, noticeably confirmed in Seventeenth-Century English poetry. This paper highlights the interrelationship between literary art and political factors, beginning with the Petrarchan tradition that fosters the justly famed sonnets and sonnet sequences of the Elizabethan era and after that moving on to the Metaphysical school of John Donne and the Cavalier poets under the aegis of Jonson. Our study then scrutinizes a few samples of religious (Herbert's), Puritan (Milton's) or libertine (Rochester's) poetry as produced by some of its key figures, without leaving aside the valuable verse written by women (Behn, Cavendish) or by those poets noteworthy for blending the landscape with praise for powerful figures and patrons of art (responsible for the well-known country-house poems). Making a start with the metaphysical statement "We'll build in sonnets pretty rooms", by John Donne, this paper aims to present a thorough, albeit condensed, overview of 17th-Century English Poetry, specifying the different approaches and dictions applied by each of the respective schools or groupings. The rise and development of the sonnet is hereby analyzed in the works of Wyatt, Howard, Sidney, Spenser, Shakespeare, Donne, Herbert and Milton. In a similar vein, the new universe opened up by the metaphysical idiom allows us to single out the most salient rhetorical features characterizing these poems, such as the conceit, the shocking fusion of the "new science" and philosophy, as well as the overall complexity of style that emanates from these outstanding compositions. The next constellation to be dealt with 
encompasses those Cavalier poets that wrote brief and "neat" poems that deliberately eschew intellectualism or semantic obscurity. This will lead to an indispensable consideration of religious poetry, a variety that also merits close reading, as there is a significant array of writers who devoted their efforts to devotional introspection, sincere confessionalism and the dissemination of the Christian faith. For the sake of the contrast, we also examine libertine poetry, well surpassing the Cavalier "carpe diem" theme in order to embrace an often cruder morality. Finally, we intend to illustrate the achievement and social triumph, of a sort, of several women writers, to the effect of ending our tour with the poetry that more effectively blends landscape with politics and society ("country-house poems").

Keywords: Metaphysical Poetry, Court Poets, Devotional Poets, Female Wits, Country-House Poems.

\title{
„SONETUOSE MES KURSIME GRAŽIĄ VIEŠPATIJĄ“
}

\author{
Juan de Dios Torralbo Caballero
}

Kordobos universitetas, Ispanija

Santrauka. Visuomenès ir literatūros sąsajos - akivaizdžios, jas iliustruoja ir septynioliktojo šimtmečio Anglijos poezija. Šiame straipsnyje nagrinèjami susiję literatūros meno ir politikos faktoriai, pradedant Petrarkos tradicija, kuri išpuoselèjo pelnytai išgarsèjusius sonetus ir karalienès Elžbietos eros sonetu sekvencijas, ir véliau - Džono Dono (John Donne) atstovaujamoje „metafiziku mokykloje“ bei poetu rojalistu (Cavalier), kuriu žinomiausias yra Benas Džonsonas (Ben Jonson), kūryboje. Studijoje taip pat pateikiama kelių iškiliausių religinès (Džordžo Herberto (George Herbert), puritoniškosios (Džono Miltono (John Milton) ir laisvamaniškosios (Džono Vilmoto iš Ročesterio (John Wilmot, 2nd Earl of Rochester) poezijos atstovu pavyzdžiu analizé, nepamirštant ir vertingosios moteru (Afros Ben (Aphra Behn), Margaretos Kavendiš (Margaret Cavendish) poezijos bei kürybos tų poetu, kurie žinomi „dvarų eilemis“, pasižyminčiomis gražia aprašomo gamtovaizdžio ir šlovinamu iškiliu asmenybių bei mecenaty̨ derme. Remiantis Džono Dono metafiziniu teiginiu „Sonetuose mes kursime gražia viešpatija“" straipsnyje keliamas tikslas pateikti trumpa, bet išsamią XVII amžiaus Anglijos poezijos apžvalga ir aptarti j̣vairu poezijos mokyklu bei sroviu skirtingus požiūrius bei išraiškos būdus. Straipsnyje nuodugniai analizuojamos soneto atsiradimo ir vystymosi tendencijos Tomo Vajato (Thomas Wyatt), Henrio Hovardo (Henry Howard), Filipo Sidnio (Philip Sidney), Edmundo Spenserio (Edmund Spenser), Viljamo Šekspyro (William Shakespeare), Džono Dono, Džordžo Herberto ir Džono Miltono kūriniuose. Kaip ir straipsnio pavadinime cituojamoje metafizineje idiomoje, akivaizdūs reikšmingiausi šiu poezijos kürinių retorikos bruožai - i̇mantrios metaforos, „naujojo mokslo" ir filosofijos susipynimas bei visuminis stiliaus sudètingumas, kuriuo alsuoja šie išskirtiniai küriniai. Straipsnyje nagrinejama ir kitos poetu rojalistu plejados kūryba, kurie raše trumpas ir tvarkingas eiles, sąmoningai vengdami perdèto intelektualumo ar semantiniu įmantrybiu - tai religinè poezija, nusipelnanti atidaus skaitymo, kadangi dauguma 
poetu visq dèmesị skyrè introspekcijai, nuoširdžiam dievybès išpažinimui ir krikščioniškojo tikejimo skleidimui.

Kontrasto dèlei pateikiama ir laisvamaniškosios poezijos analizé. Ji gerokai pralenkia rojalistinés poezijos „Carpe Diem“ tematika, siekdama apdainuoti ir dažnai šiurkštesne moralę. Galiausiai, straipsnyje atskleidžiami ir moterų poečiu bei rašytoju pasiekimai bei ju socialinis triumfas. Taigi, apžvelgiama visa ta poezija, kurioje kraštovaizdžio aprašymas efektyviausiai susipina su politikos ir visuomenès aktualijomis („dvaru eilès“).

Reikšminiai žodžiai: metafizikų poezijos mokykla, rojalistų poezija, religinè poezija, moterys poetès, dvaru eiles.

Juan de Dios Torralbo Caballero, Kordobos universiteto Humanitariniu moksly fakulteto Anglu ir vokiečiu kalbu studiju katedros docentas. Moksliniu interesu sritys: anglu poezija, moterys poetés, smulkieji literatūros žanrai (XVII ir XVIII a.), anglu poezijos vertimas ir paplitimas Ispanijoje.

Juan de Dios Torralbo Caballero, University of Cordoba, Faculty of Humanities. Department of English and German Studies, Associate Profesor. Research interests: English Poetry, Female poets, Short Fiction (17th and 18th Centuries), Reception and Translation of English Poetry in Spain. 